of sixty miles, by an iceberg or a glacier in the great Ice Age; and the ground around it is to be inclosed, turfed, planted, and set with rustic seats. A fine day, and the novel proceeding, drew a large and attentive crowd; a short, bright service was conducted with the aid of an unusually good village choir; and the big stone set up by Joshua at Shechem formed the text for a sermon intended to stamp the boulder as a religious no less than a scientific monument.

This charming little idyll is the closing chapter in a story which might claim to share the title made historic by a great geologist. Five years ago the present rector, coming to Stockton, found the boulder lying in a ditch, into which it had been rolled from its inconvenient position by the roadside. A hazy clerical belief that it was "Druidic" had saved it from complete destruction; but it was the cockshy of all the children, bonfires were lighted on it occasionally, and it lay at the mercy of every field club which might come hammering that way. Large, glaciated, and of granite, it was clearly worth preserving. The new rector told its probable history from the pulpit and the village mind was roused. Reports came in of other big stones far and near, some of which were also of glacial origin ; the quarrymen in the adjoining limeworks, digging down to a smaller piece of granite and some beautifully striated blocks of sandstone, protected instead of breaking them; and by following up the hint thus given, a fine bed of boulder clay was uncovered, shown to Dr. Crosskey, and inserted in the Boulder Committee Report of the British Association. The fame of the great stone spread; visitors came to see it ; the Stocktonians, who had through frequent lectures learnt its scientific value, became proud of their "Pibble" and of their ability to instruct their neighbours; the subscription point was reached, and money found to move and rail in the treasure; the surrounding villages finally emptied themselves to attend the consecration service, and Stockton is at this moment, like douce Davie Deans, "as uplifted as a midden-cock on pattens."

The moral of the story is twofold. First: what has been done in Stockton ought to be done in scores of other villages. This boulder was the first link in a chain of evidence, lengthening ever since, in favour of a new and pregnant probability, the current of an ice-sheet from the Charnwood Forest heights across the table-land of South Warwickshire. In countless corners more lie similar monuments, unknown and doomed, which, if thus preserved and studied, would afford the keys to like problems in geology. And secondly : the clergy ought to do it. Our country parsons are, if they could be educated to see it, the natural discoverers and conservators of local relics ; with the opportunities they have and the attainments they ought to possess, they might in their mere leisure write such a scientific history of England as no country has yet possessed. Let them read the delightful chapter in $L e$ Maudit, which paints the Cure Julio in his Pyrenean parish, and in order that they may be qualified to imitate him, let the bishops be wise in their generation, and exact a knowledge of some branch of natural history from every candidate for Orders.

\section{REPORT OF THE PARIS OBSERVATORY FOR} THE YEAR I 882

$\mathrm{W}^{\mathrm{E}}$ have received from Admiral Mouchez, the Director of the Paris Observatory, the report on the state of that Observatory for the past year, and as we recently made reference to the state of our own Greenwich Observatory on the occasion of the visitation which took place at the beginning of the present month, we think it may interest our readers. if we make a few extracts from this report of Admiral Mouchez.

The report opens with a complaint that the service of the Observatory has been very considerably deranged by the preparations for the transit of Venus. Not only did the various members of the expedition attend at the $\mathrm{Ob}$ servatory in order to be trained either in photography or in the use of the artificial transit, but no less than five of the personnel of the Observatory themselves took part in the work. At the same time, says Admiral Mouchez, the past year may take rank with any of its predecessors when the increased work of the Observatory is taken into account, for during this time an extension of ground has taken place, the equatorial coudé has been installed, and several underground chambers have been constructed for the purpose of studying magnetism and terrestrial physics generally. Curiously enough, one of the grounds on which the addition of magnetical studies to the work of the Observatory is urged is, that the cloudy skies of Paris so frequently interrupt the purely astronomical observations, that, without some such work as it is now proposed to add, the observers would frequently have little to do.

Among the purely astronomical work of the Observatory which has been going on for the last four years is that of the revision of Lalande's catalogue of stars, numbering 40,000. Concerning this work, we are informed that the General Catalogue, which will form eight volumes in quarto, is well in hand, and it is hoped that two volumes will be published each year, or at all events four volumes during the next three years. To assist in the construction of the catalogue, 110,000 meridian observations have been made during the last four years.

The employment of ordinary equatorials in an observatory, remarks Admiral Mouchez, necessitates a continual change of position of the observer, he being compelled to follow the movement of the eyepiece into positions which are often inconvenient and fatiguing, whilst the heavy dome of the observatory has also to be constantly rotated to follow the motion of the telescope. In order to obviate the necessity for this, M. Lœwy conceived the idea of adapting to the equatorial the system of "lunette brisée," employed first in England, and afterwards to a greater extent in Germany, especially in small transit instruments.

The new coudé equatorial may be thus described:-The polar axis of the instrument is supported at its extremities on two pillars like a meridian instrument. Round this axis the telescope turns, forming a right angle at the lower support. By means of a mirror placed at the summit of this angle the light is reflected along the pierced axis, at the end of which the eyepiece or the micrometer is placed. Under these conditions, with the telescope at rest, the equatorial stars pass across the observer's field of view. But of course the telescope must not be limited to the observation of equatorial stars. In order to secure the observation of other stars, a mirror free to rotate is placed before the object-glass and connected with the declination circle. The inclination of this mirror may be changed so as to throw the light coming from a star of any declination into the tube. This arrangement therefore permits the observer to explore every part of the heavens without quitting his position at one end of the polar axis. The telescope may, practically, by a rotation of this axis, be directed towards any part of the celestial equator, whilst a star of any declination may be made to throw its light down the broken telescope by means of the external mirror. It might be imagined that in this latter case the double reflection would result in the loss of a good deal of light, but we read that the preliminary experiments have shown that this is not the case, and that the polish and figure of the mirrors are very satisfactory. They are silvered, and of course can be easily repolished. We should add that this instrumert, now one of the actualities of the Observatory, is due to the liberality of Mr. Bischoffsheim.

With regard to more strictly physical observations, those who have made their complaint respecting the 
recent weather in England will perhaps find a grain of consolation in the statement that $\mathrm{M}$. Thollon, who comes every summer to work in connection with this part of the Observatory, spent his whole summer there last year without being able to make a single observation. M. Egoroff, Professor of Physics at Warsaw, was, we learn, occupied during the months of July and August, as in preceding years, with the spectroscopic study of atmospheric absorption, working with a beam of electric light sent from Mont-Valérien to the Observatory.

Most of our readers are aware that the French Government has, as we think wisely, determined to separate the special meteorological investigations from the astronomical work of the Observatory. In consequence of this decision, Admiral Mouchez is now making meteorological observations of possibly a still higher value, with the special object of determining the different corrections, such as for refraction, to be applied to the astronomical observations.

The magnetical observatory which is now being completed will evidently be one of the first order. Six subterranean chambers of constant temperature have been built under the best possible conditions of isolation and stability. An outer wall of nearly $2 \mathrm{~m}$. thickness incloses a rectangular space $40 \mathrm{~m}$. in length, and $14 \mathrm{~m}$. wide, completely impervious to moisture. The observing chambers, of which there are four of $5 \mathrm{~m}$. by $4 \mathrm{~m}$., and t:vo of $6 \mathrm{~m}$. by $5 \mathrm{~m}$., are constructed in this space, being i iolated from its walls by passages $2 \mathrm{~m}$. wide. The walls of the observing chambers them selves are 80 centimetres thick; they communicate with each other by doors $1 \frac{1}{2} \mathrm{~m}$. wide, and have a height of $3.65 \mathrm{~m}$. The vaulted r jof, $1 \mathrm{~m}$. thick, is covered by earth to the thickness of $2 \mathrm{~m}$., whilst grass and plants protect the soil from the direct rays of the sun, and from frost. The observing chambers can either be lighted by gas or by reflection from without.

Advantage has been taken of the existence of these chambers by placing in them the clocks from which the time is distributed throughout Paris, but in spite of all precautions it is unfortunately discovered that the chambers are not altogether free from minor trepidations resulting from the traffic of the streets. It is proposed therefore to place the apparatus for the study of the vertical and slow movements of the soil to a gallery in the Catacombs $27 \mathrm{~m}$. below the surface. This apparatus has been constructed and is ready for use.

Among the meteorological work to be done with the object to which we have previously referred is included a series of observations from a captive balloon. This is of such a size that with ordinary gas in calm weather it can take self-registering barometers, thermometers, and hygrometers up to a height of $500 \mathrm{~m}$., and with pure hydrogen it can ascend to a height of $800 \mathrm{~m}$. It has been found by experiment that the balloon cannot be well managed if the air has a velocity greater than $4 \mathrm{~m}$. or $5 \mathrm{~m}$. per second; but this is not regarded as being inconvenient, because it $i$ d during complete calm that those great and frequent inversions of the law of decrease of temperature which most sensibly interfere with astronomical refraction, manifest themselves.

Simultaneous observations will be made on the meridian of the Observatory of Paris, north at the Observatory of Montmartre, and south at the Observatory of Montsouris.

The construction of the great refractor of $16 \mathrm{~m}$. focal length with its dome of $20 \mathrm{~m}$. in diameter is going on steadily. The object-glass worked by M. Martin is already finished, and the ground on which the Observatory is to be built is now prepared. There are some interesting details in the report touching the dome, the dimensions of which we learn will be the same as that of the Panthéon, and the largest ever attempted.

In insisting upon such a dome turning with ease, it must not be forgotten that it would be useless to construct one of such dimensions, unless steps were taken to prevent the ill effects which would arise from any displacement or deformation of the soil on which the Observatory is to be erected, or the walls of the Observatory itself. The arrangement which is to be adopted in the construction of this dome is that proposed by M. Eiffel. In order to reduce to a minimun. the resistance due to friction on circular rollers, M. Eiffel proposes to float the dome by means of circular caisson plunged in a receptacle of the same form, filled with a liquid which will not freeze, such as an aqueous solution of chloride of magnesium. An experiment made with a small model gave hopes of the most satisfactory results with this arrangement. There is much originality in the idea, and at the Paris Observatory more than anywhere else perhaps it is necessary that some such arrangement as this should be adopted, for it must not be forgotten that the Observatory is situated over the Catacombs, one result of which has been that for many years the pillars of the meridian circle erected in the gardens have gradually inclined towards the east in consequence of the displacement of the soil. If the same thing were to happen to the Observatory for the great equatorial, there is little doubt that before many years were over the dome would be quite immovable, whereas with Eiffel's floating arrangement, whatever be the change in level within season due to such a cause as we bave named, the dome would still turn.

Another point which is engaging the attention of the Director is the erection of an astronomical observatory on the Pic du Midi, at a height of $2859 \mathrm{~m}$. At this elevation, according to General de Nansouty, it is easy to read at night by the light of the stars alone, and fifteen or sixteen Pleiades are visible to the naked eye. It is indeed time that the importance of the possibility of observations at great heights received a fuller recognition. When the astronomical party were in the Rocky Mountains in 1878 , to observe the eclipse of the sun there, three American observers had no difficulty in detecting the satellites of Jupiter every night with the naked eye. Notbing could show better the purity and transparency of the air than this, and to establish these facts is to establish also the necessity for utilising them. It is intended that any astronomer who wishes to make any special researches may take advantage of this Pic du Midi Observatory. At the same time, however, astronomers will be sent from the Paris Observatory to profit by the clear skies of the south at those times when the climate of Paris reduces the number of possible observations in the Observatory itself. It is pointed out that not only the science of astronomy, but physics, chemistry, and physiology, will probably derive great benefit from the institution of such an observatory as this.

\section{NOTES}

The Royal Society Soirée last Wednesday was as successful as usual, though the absence of the president, Mr. Spottiswoode, through illness, was to be regretted. From inquiries last night we are glad to learn that Mr. Spottiswoode, who is suffering from Roman fever, is going on very well.

THE candidates selected by the Council of the Royal Society, whose names we gave in NATURE, vol. xxvii. p. 614, were elected last Thursday.

DR. Michael Foster has, in accordance with unanimous expectation, been elected to the newly established Professorship of Physiology in the University of Cambridge; and Dr. Alexander Macalister, F.R.S., Professor of Comparative Anatomy and Zoology in the University of Dublin, has been elected to the Professorship of Anatomy, vacant by the resignation of Prof. Humphry. 